\title{
FAKTOR-FAKTOR PENYEBAB TERJADINYA PENYAKIT OSTEOPOROSIS PADA LANSIA DI UPT PELAYANAN SOSIAL LANJUT USIA DI WILAYAH BINJAI TAHUN 2017
}

\author{
Factors Causing Osteoporosis Disease on Elderly in Service Age Social \\ UPT in Binjai Region 2017
}

\author{
Leny Suarni ${ }^{1}$ \\ ${ }^{1}$ Dosen Akademi Keperawatan Sehat Binjai \\ E-mail: lenysuarni2016@gmail.com
}

\begin{abstract}
Abstrak
Osteoporosis merupakan penyakit yang menyerang tulang dimana keadaan tulang menjadi rapuh (flagela) dan mudah dan mengalami patah (fraktur). Banyak faktor penyebab Osteopororsis ini adalah salah satunya faktor kekurangan kalsium terutama dimana di masa kecil sampai remaja. Dengan melihat kondisi di atas penulis ingin melakukan penelitian yang bertujuan untuk mengetahui Faktor-Faktor Penyebab Terjadinya Penyakit Osteoporosis Pada Lansia Di UPT Pelayanan Lanjut Usia Binjai Tahun 2017.

Penelitian ini bersifat Deskriptif dengan rancangan cross sectional yang dilakukan kepada lansia dengan jumlah 25 orang. Pengumpulan data ini di lakukan dengan cara Kuesioner. Hasil penelitian ini menunjukan bahwa faktor-faktor penyebab terjadinya penyakit osteoporosis adalah faktor kekurangan kalsium sebanyak 18 orang (72\%), faktor obat-obatan sebanyak 20 orang (80\%), faktor merokok dan mengkonsumsi alkohol sebanyak 10 orang (40\%), faktor kurang gerak badan sebanyak 19 orang (76\%), dan faktor penyakit sebanyak 15 orang $(60 \%)$.

Jadi, dapat disimpulkan bahwa penyebab osteoporosis yang paling dominan pada lansia di UPT Pelayanan Sosial Lanjut Usia di Wilayah Binjai Tahun 2017 adalah Obat-Obatan 80\%. Maka dari itu diharapkan pada lansia untuk kurang mengkonsumsi Obat-obatan yang dapat menyebabkan Osteoporosis.

Kata Kunci : Osteoporosis, Faktor-Faktor Penyebab Osteoporosis, Lansia
\end{abstract}

\begin{abstract}
Osteoporosis is a disease that attacks the bone where the bone becomes brittle (flagella) and is easily broken and fractured. Many of the factors that cause Osteopororsis are one of them is calcium deficiency, especially in childhood to adolescence. By looking at the conditions above, the writer wants to do a research that aims to find out the Factors Causing Osteoporosis in the Elderly in the 2017 Binjai Elderly Service Unit. This research is descriptive with a cross sectional design carried out for the elderly with 25 people. This data collection is done by questionnaire. The results of this study indicate that the factors that cause osteoporosis are calcium deficiency factors as many as 18 people (72\%), drug factors as many as 20 people $(80 \%)$, smoking factors and consuming alcohol as many as 10 people $(40 \%)$, factors lack of exercise as many as 19 people (76\%), and disease factors as many as 15 people $(60 \%)$. So, it can be concluded that the most dominant cause of osteoporosis in the elderly in the UPT for Elderly Social Services in the Binjai Region in 2017 is $80 \%$ Medicines. Therefore, it is expected that the elderly will consume less drugs that can cause Osteoporosis.
\end{abstract}

Keywords: Osteoporosis, Causes of Osteoporosis, Elderly

\section{PENDAHULUAN}

Osteoporosis merupakan penyakit skeletal sistemik yang di tandai dengan massa tulang yang rendah dan kerusakan mikroarsitektur jaringan tulang, yang mengakibatkan meningkatnya fraglitas tulang sehingga tulang cenderung untuk mengalami fraktur spontan atau akibat trauma minimal (Consensus Development Conference, 1993).

Osteoporosis lebih banyak terjadi pada wanita dari pada pria. Hal ini disebabkan pengaruh hormon estrogen yang mulai menurun kadarnya dalam tubuh sejak usia 35 tahun sedangkan pada pria hormon testoteron turun pada usia 65 tahun. Menurut 
statistik dunia 1 dari 3 wanita rentan terkena penyakit osteoporosis.

Insiden osteoporosis meningkat sejalan dengan meningkatnya populasi usia lanjut. Pada tahun 2005 terdapat 18 juta lanjut usia di Indonesia, jumlah ini akan bertambah hingga 33 juta pada tahun 2020 dengan usia harapan hidup mencapai 70 tahun. Menurut data statistik Itali tahun 2004 lebih dari 44 juta orang Amerika mengalami osteopenia dan osteoporosis. Pada wanita usia $\geq 50$ tahun terdapat $\quad 30 \%$ osteoporosis, $\quad 37-54 \%$ osteopenia dan $54 \%$ berisiko terhadap fraktur osteoporotik.

Osteoporosis merupakan salah satu dari tiga penyakit kronik utama yang disebabkan karena faktor usia termasuk juga pada wanita postmenopause. Menopause berhubungan dengan reduksi hormon estrogen pada wanita yang dapat mengakibatkan menurunnya kepadatan tulang sehingga terjadi osteoporosis.

Menurut WHO (1994), angka kejadian patah tulang (fraktur) akibat osteoporosis di seluruh dunia mencapai angka 1,7 juta orang dan diperkirakan angka ini akan terus meningkat hingga mencapai 6,3 juta orang pada tahun 2050 dan $71 \%$ kejadian ini akan terdapat di negara-negara berkembang. Di Indonesia $19,7 \%$ dari jumlah lansia atau sekitar 3,6 juta orang diantaranya menderita osteoporosis. Lima provinsi dengan risiko osteoporosis lebih tinggi adalah Sumatra Selatan $(27,75 \%)$, Jawa Tengah $(24,02 \%)$, Yogyakarta $(23,5 \%)$, Sumatra Utara $(22,82 \%)$, Jawa Timur (21,42\%), Kalimantan Timur (10,5\%). Prevalensi wanita yang menderita osteoporosis di Indonesia pada golongan umur 50-59 tahun yaitu $24 \%$ sedang pada pria usia $60-70$ tahun sebesar $62 \%$.

Berdasarkan survei pendahuluan yang dilakukan peneliti di UPT pelayanan sosial lanjut usia wilayah binjai, terdapat 25 orang lansia penderita penyakit osteoporosis. Maka peneliti tertarik dan untuk meneliti tentang Faktor-Faktor Terjadinya Penyakit Osteoporosis Pada Lansia Di UPT Sosial Lanjut Usia Binjai Tahun 2017.

\section{METODE}

Penelitian ini menggunakan jenis penelitian deskriptif yaitu suatu metode penelitian yang dilakukan dengan tujuan utama untuk membuat gambaran atau deskriptif tentang suatu keadaan secara objektif. Penelitian ini dilaksanakan UPT Pelayanan Sosial Lanjut Usia Binjai. Waktu Penelitian telah melakukan survei awal pada tanggal 17 Maret sampai 10 April 2017.

Populasi dalam penelitian ini adalah seluruh penderita penyakit osteoporosis di UPT pelayan sosial Lanjut Usia Binjai sebanyak 25 orang.

Sampel dalam penelitian ini adalah sebagian lansia yang berada di UPT pelayanan sosial lanjut usia yang mengalami penyakit osteoporosis sebanyak 25 orang.

Teknik pengambilan sampel dalam penelitian ini menggunakan Teknik total sampling yaitu semua populasi dijadikan sampel.

\section{HASIL DAN PEMBAHASAN}

Tabel 4.1 Distribusi Responden Berdasarkan Umur di Panti Sosial UPT Pelayanan Sosial lanjut Usia di Wilayah binjai Tahun 2017

\begin{tabular}{llll}
\hline No. & $\begin{array}{l}\text { Umur } \\
\text { (Tahun) }\end{array}$ & $\begin{array}{l}\text { Freku- } \\
\text { ensi }\end{array}$ & $\begin{array}{l}\text { Persen- } \\
\text { tase }(\boldsymbol{\%})\end{array}$ \\
\hline 1 & $60-70$ & 10 & 40 \\
2 & $71-80$ & 10 & 40 \\
3 & $81-90$ & 5 & 20 \\
\hline Jumlah & $\mathbf{2 5}$ & $\mathbf{1 0 0}$ \\
\hline
\end{tabular}

Dari tabel di atas dapat dilihat bahwa mayoritas responden berusia 60-70 tahun dan 71-80 tahun masing-masing 10 orang atau $40 \%$.

Tabel 4.2 Distribusi Responden Berdasarkan Jenis Kelamin di Panti sosial UPT Pelayanan Sosial Lanjut Usia di Wilayah Binjai Tahun 2017

\begin{tabular}{l|l|l|l}
\hline No. & $\begin{array}{l}\text { Jenis } \\
\text { Kelamin }\end{array}$ & $\begin{array}{l}\text { Frek } \\
\text { uensi }\end{array}$ & $\begin{array}{l}\text { Perse } \\
\text { ntase } \\
(\boldsymbol{\%})\end{array}$ \\
\hline 1 & Laki-laki & 14 & 56 \\
2 & Perempuan & 11 & 44 \\
\hline \multicolumn{2}{|l}{ Jumlah } & $\mathbf{2 5}$ & $\mathbf{1 0 0}$ \\
\hline
\end{tabular}


Dari tabel 4.2 menunjukan bahwa sebagian besar berjenis kelamin laki-laki yaitu 14 orang (56\%).

Tabel 4.3 Distribusi Responden Berdasarkan Tingkat Pendidikan di Panti Sosial UPT Pelayanan Sosial Lanjut Usia di Wilayah Binjai Tahun 2017

\begin{tabular}{l|l|l|l}
\hline No. & $\begin{array}{l}\text { Pendi- } \\
\text { dikan }\end{array}$ & $\begin{array}{l}\text { Freku- } \\
\text { ensi }\end{array}$ & $\begin{array}{l}\text { Perse } \\
\text { ntase } \\
(\%)\end{array}$ \\
\hline 1 & SD & 15 & 60 \\
2 & SMP & 5 & 20 \\
3 & SMA & 5 & 20 \\
\hline \multicolumn{2}{l}{ Jumlah } & $\mathbf{2 5}$ & $\mathbf{1 0 0}$ \\
\hline
\end{tabular}

Berdasarkan tabel 4.3 sebagian besar responden pendidikan SD yang terdiri dari 15 orang atau $60 \%$.

Tabel 4.4. Distribusi Responden Pada Lansia Berdasarkan Faktor Kekurangan Kalsium di UPT Pelayanan Sosial Lanjut Usia di Wilayah Binjai Tahun 2017

\begin{tabular}{|c|c|c|c|}
\hline $\begin{array}{l}\text { No } \\
\text {. }\end{array}$ & $\begin{array}{l}\text { Akibat } \\
\text { faktor } \\
\text { Kekurang- } \\
\text { an Kalsium }\end{array}$ & $\begin{array}{l}\text { Frek } \\
\text { u- } \\
\text { ensi }\end{array}$ & $\begin{array}{l}\text { Per- } \\
\text { senta } \\
\text { se } \\
(\%)\end{array}$ \\
\hline 1 & Dominan & 18 & 72 \\
\hline 2 & $\begin{array}{l}\text { Tidak } \\
\text { Dominan }\end{array}$ & 7 & 28 \\
\hline \multicolumn{2}{|c|}{ Jumlah } & 25 & 100 \\
\hline $\begin{array}{l}\text { menut } \\
\text { mend } \\
\text { faktor } \\
\text { orang }\end{array}$ & $\begin{array}{l}\text { Berdasarkan } \\
\text { jukan bahwa } \\
\text { rita Osteoporosi } \\
\text { kekurangan kals } \\
(72 \%) \text {. }\end{array}$ & $\begin{array}{r}\text { tabel } \\
\text { respo } \\
\text { is di }\end{array}$ & $\begin{array}{r}4.4 \\
n \quad \text { yang } \\
\text { arenakar } \\
\text { nyak } 18\end{array}$ \\
\hline
\end{tabular}

Tabel 4.5. Distribusi Responden pada Lansia akibat Faktor Obat-obatan di UPT Pelayanan Sosial Lanjut Usia di Wilayah Binjai Tahun 2017

\begin{tabular}{llll}
\hline No. & $\begin{array}{l}\text { Akibat } \\
\text { faktor } \\
\text { Obat- } \\
\text { obatan }\end{array}$ & $\begin{array}{l}\text { Fre- } \\
\text { kuen } \\
\text { si }\end{array}$ & $\begin{array}{l}\text { Perse } \\
\text { ntase } \\
(\boldsymbol{\%})\end{array}$ \\
\hline 1 & $\begin{array}{l}\text { Dominan } \\
\text { Tidak }\end{array}$ & 20 & 80 \\
2 & 5 & 20 \\
\hline
\end{tabular}

Dominan

\begin{tabular}{lcr}
\hline Jumlah & 25 & $\mathbf{1 0 0}$ \\
\hline Berdasarkan & tabel & 4.5 \\
menunjukan bahwa & responden yang \\
menderita Osteoporosis dikarenakan faktor \\
obat-obatan sebanyak 20 orang (80\%).
\end{tabular}

Tabel 4.6 Distribusi Responden pada Lansia akibat faktor Meerokok dan Mengkonsumsi Alkohol di UPT pelayanan Sosial Lanjut Usia di Wilayah Binjai Tahun 2017

\begin{tabular}{|c|c|c|c|}
\hline No. & $\begin{array}{l}\text { Akibat } \\
\text { faktor } \\
\text { Merokok } \\
\text { dan } \\
\text { Mengko } \\
\text { nsumsi } \\
\text { Alkohol } \\
\end{array}$ & $\begin{array}{l}\text { Frek } \\
\text { uensi }\end{array}$ & $\begin{array}{l}\text { Persent } \\
\text { ase }(\%)\end{array}$ \\
\hline 1 & Dominan & 10 & 40 \\
\hline 2 & $\begin{array}{l}\text { Tidak } \\
\text { Dominan }\end{array}$ & 15 & 60 \\
\hline \multicolumn{2}{|c|}{ Jumlah } & 25 & 100 \\
\hline \multicolumn{4}{|c|}{$\begin{array}{l}\text { Berdasarkan } \\
\text { menunjukan bahwa responden yang } \\
\text { menderita Osteoporosis di karenakan } \\
\text { faktor merokok dan mengkonsumsi } \\
\text { alkohol sebanyak } 10 \text { orang }(40 \%) \text {. }\end{array}$} \\
\hline
\end{tabular}

Tabel 4.7 Distribusi Responden Pada Lansia Akibat Faktor Kurang Gerak Badan di UPT Pelayanan Sosial Lanjut Usia di Wilayah Binjai Tahun 2017

\begin{tabular}{llll}
\hline No. & $\begin{array}{l}\text { Akibat } \\
\text { faktor } \\
\text { Kurang } \\
\text { Gerak } \\
\text { Badan }\end{array}$ & $\begin{array}{l}\text { Frek } \\
\text { uensi }\end{array}$ & $\begin{array}{l}\text { Perse } \\
\text { ntase } \\
(\boldsymbol{\%})\end{array}$ \\
& & \\
\hline 1 & Dominan & 19 & 76 \\
2 & Tidak & 6 & 24 \\
& Dominan & & \\
\hline Jumlah & $\mathbf{2 5}$ & $\mathbf{1 0 0}$ \\
\hline
\end{tabular}

Tabel $\quad 4.8 \quad$ Distribusi Responden Berdasarkan faktor Penyakit Pada Lansia di Upt Pelayana Sosial Lanjut Usia di Wilayah Binjai Tahun 2017

\begin{tabular}{l|l|l|l}
\hline No. & $\begin{array}{l}\text { Akibat } \\
\text { faktor }\end{array}$ & $\begin{array}{l}\text { Freku } \\
\text { ensi }\end{array}$ & $\begin{array}{l}\text { Per- } \\
\text { sen- }\end{array}$ \\
\hline
\end{tabular}




\begin{tabular}{l|l|l|l}
\hline & penyakit & & $\begin{array}{l}\text { tase } \\
(\boldsymbol{\%})\end{array}$ \\
\hline 1 & $\begin{array}{l}\text { Dominan } \\
\text { Tidak } \\
\text { Dominan }\end{array}$ & 15 & 60 \\
& 10 & 40 \\
\hline \multicolumn{2}{l}{ Jumlah } & $\mathbf{2 5}$ & $\mathbf{1 0 0}$ \\
\hline
\end{tabular}

$\begin{array}{lll}\text { Berdasarkan } & \text { tabel } \quad 4.8\end{array}$ menunjukan bahwa responden yang menderita osteoporosis dikarenakan faktor penyakit sebanyak 15 orang atau $60 \%$.

Dalam penelitian ini adalah membahas hal-hal yang berkaitan dengan pemilihan yang telah di ketahui pada bagian pendahuluan bahwa tujuan umum penelitian untuk untuk mengetahui gambaran kasus penderita Osteoporosis pada lansia di UPT pelayanan Sosial Lanjut Usia di Wilayah Binjai tahun 2017.

\section{Umur}

Dari tabel 4.1. dapat di lihat dari 25 orang responden berdasarkan umur, yang berumur 60-70 terdiri dari 10 orang atau $40 \%$, umur $71-80$ terdiri dari 10 atau $40 \%$ dan umur 81-90 terdiri dari 5 atau $20 \%$, cenderung mengalami Osteoporosis karena proses densitas (kepadatan tulang) hanya berlangsung sampai seseorang berusia 25 tahun. Selanjutnya, kondisi tulang akan tetap (konstan) hingga usia 40 tahun, setelah 40 tahun densitas tulang mulai berkembang secara perlahan dan akan berlangsung terus menerus sepanjang sisa hidup (Wirakusumah, 2007).

\section{Jenis Kelamin}

Dari tabel di atas dapat di lihat dari 25 orang responden berdasarkan jenis kelamin yaitu laki-laki 14 orang atau 56\% dan perempuan 11 orang atau $44 \%$. Ternyata dari hasil penelitian laki-laki lebih banyak menderita Osteoporosis. Hal ini di sebabkan jumlah lansia laki-laki lebih banyak dari pada perempuan di UPT

Pelayanan Sosial Lanjut Usia di Wilayah Binjai. Ini juga di sebabkan laki-laki lebih sering merokok dan mengkonsumsi alkohol dari pada perempuan.

\section{Pendidikan}

Dari tabel 4.3 dapat di lihat dari 25 responden berdasarkan tingkat pendidikan yaitu SD terdiri dari 15 orang atau $60 \%$, SMP terdiri dari 5 orang atau $20 \%$ dan SMA terdiri dari 5 orang atau $20 \%$. Ternyata dari hasil penelitian berdasarkan pendidikan, yang berpendidikan SD cenderung mengalami Osteoporosis dari data epidemiologi menunjukan bahwa golongan penduduk yang berpendidikan rendah atau buta huruf menunjukan kurang tahu pengetahuan termasuk pengetahuan tentang suatu penyakit.

Berdasarkan tabel 4.4 dapat diketahui bahwa dari 25 responden penelitian berdasarkan faktor kekurangan kalsium pada lansia yang dominan menderita Osteoporosis ada 18 orang atau $72 \%$ dan yang tidak dominan ada 7 orang atau $28 \%$. Bila penyebab faktor dari penyakit Osteoporosis pada lansia karena dari beberapa penelitian mengungkapkan bahwa akibat kekurangan kalsium terutama di masa kecil hingga remaja, saat pembentukan maksimal, dapat menyebabkan utama Osteoporosis (Waluyo, 2002).

Berdasarkan tabel 4.5 dapat di ketahui bahwa dari 25 responden penelitian berdasarkan faktor gangguan obat-obatan yang dominan menderita Osteoporosis ada 20 orang atau $80 \%$ dan yang tidak dominan ada 5 orang atau $20 \%$. Bisa menyebabkan Osteoporosis karena apabila sering mengkonsumsi obat-obatan, minuman dapa mengurangi penyerapan kalsium contohnya obat golonga steroid (Wirakusumah, 2007).

Berdasarkan taber 4.6 dapat diketahui bahwa dari 25 responden penelitian berdasarkan faktor merokok dan mengkonsumsi alkohol yang dominan menderita Osteoporosis ada 10 orang atau $40 \%$ dan tidak dominan ada 15 orang orang atau 60\%. Hal ini karena mengkonsumsi minuman yang mengandung alkohol dapat menurunkan masa tulang sehingga terjadi kekurangan kalsium. Begitu juga dengan merokok dapat menghambat osteoblas yang berfungsi membentuk sel-sel tulang. Berdasarkan tabel 4.7 dapat diketahui bahwa dari 25 responding penelitian berdasarkan faktor kurang gerak 
badan yang dominan menderita Osteoporosis ada 19 orang atau $76 \%$ dan yang tidak dominan ada 6 orang atau $24 \%$. Hal ini dapat di karenakan di ungkapkan pada masa muda dan remaja kurang gerak badan dapat mengurangi puncak masa tulang. Di masa lanjut usia kurang gerak badan membuat lemahnya otot sehingga beresiko patah tulang.

Berdasarkan tabel 4.8 dapat di ketahui dari 25 responden penelitian berdasarkan faktor penyakit yang yang dominan menderita Osteoporosis ada 15 orang atau $60 \%$ dan yang tidak dominan ada 10 otang atau 40\%. Faktor dari penyakit Osteoporosis pada lansia dari beberapa penelitian mengungkapkan bahwa faktor penyakit dapat menyebabkan Osteoporosis misalnya diabetes militus dan kanker (Waluyo : 2002).

Berdasarkan hasil penelitian yang dilakukan maka dapat di tarik beberapa kesimpulan dan selanjutnya saran yang mungkin bermanfaat khususnya dalam meningkatkan pengetahuan para lansia tentang faktorfaktor penyebab terjadinya penyakit osteoporosis di UPT Pelayanan Sosial Lanjut Usia di Wilayah Binjai Tahun 2017.

1. Penelituan pada tinjauan faktor-faktor penyebab terjadinya Osteoporosis pada lansia telah di lakukan dengan baik, berkat kerja sama antar pegawai yang ada di UPT Pelayanan Soaial Lanjut Usia di Wilayah Binjai.

2. Dari hasil penelitian ini maka di ketahui bahwa faktor kekurangan kalsium menyebabkan terjadinya Osteoporosis pada lansia di UPT Pelayanan Sosial Lanjut Usia di Wilayah Binjai Tahun 2017 dengan jumlah 18 orang (72\%).

3. Dari hasil penelitian ini maka di ketahui bahwa faktor Obat-obatan menyebabkan terjadinya Osteoporosis pada lansia di UPT Pelayanan Sosial Lanjut Usia di Wilayah Binjai Tahun 2017 dengan jumlah 20 orang (80\%).

4. Dari hasil penelitian ini maka di ketahui bahwa faktor Merokok dan Mengkonsumsi alkohol menyebabkan terjadinya Osteoporosis pada lansia di UPT Pelayanan Lanjut Usia di Wilayah
Binjai Tahun 2017 dengan jumlah 10 orang (40\%).

5. Dari hasil penenlitian ini maka di ketahui bahwa faktor Kurang Gerak Badan menyebabakan terjadinya Osteoporosis pada lansia di UPT Pelayanan Sosial Lanjut Usia di Wilayah Binaji Tahun 2017 dengan jumlah 19 orang (76\%).

6. Dari hasil penelitian ini maka di ketahui bahwa Faktor Penyakit menyebabkan terjadinya Osteoporosis pada lansia di UPT Pelayanan Sosial Lanjut Usia di Wilayah Binjai Tahun 2017 dengan jumlah 15 orang $(60 \%)$.

7. Berdasarkan dari ke 5 faktor di atas dapat di simpulkan faktor Obat-Obatan yang dominan terjadinya Osteoporosis pada lansia di UPT Pelayanan sosial Lanjut Usia di Wilayah Binjai Tahun 2017 dengan jumlah 20 orang (80\%).

\section{SARAN}

Dari hasil penelitian menyatakan kepada para lansia sebagai berikut :

1. Lansia harus mengetahui lebih jauh apa yang di maksud dengan Osteoporosis, pencegahan dan penanganan yang di peroleh dari tim medis.

2. Diharapkan pada lansia agar mengontrol makanan dan aktifitas.

3. Diharapkan agar tenaga medis dapat memberikan penjelasan dan penyuluhan kepada lansia tentang faktor penyebab Osreoporosis dan pencegahannya.

\section{DAFTAR PUSTAKA}

Compaston, J. 2002. Seri Kesehatan Osteoporosis. Dian Rakyat ; Jakarta

Farida, M. 2008. Mencegah dan mengatasi Osteoporosis dengan berolahraga.. Pendidikan Jasmani Kesehatan dan Rekreasi Fakultas Keolahragaan Universitas Negeri ; Yogyakarta

La Ode, S. 2015. Asuhan Keperawatan Gerontik. Nuha Medika ;Yogyakarta

Noor, Z. 2016. Gangguan Muskulosketal. Jagakarsa ;Jakarta Selatan 12610

Rosyidin, K. 2015. Muskuloskeletal. Trans Info Media ; jakarta

Utomo, M. 2010. Jurnal Faktor-Faktor Berhubungan Dengan Kepadatan Tulang Pada Wanita Postmenopaus. 
Fakultas Kesehatan Masyarakat Universitas Muhammadiyah; Semarang

Wardhana, W. 2012. Faktor-faktor resiko Osteoporosis pada pasien dengan usia diatas 50 tahun. Program Pendidikan Sarjana Kedokteran fakultas Kedokteran Universitas Dipoegoro; Semarang. 